\title{
Observations of mesospheric sporadic sodium layers with the MU radar and sodium lidars
}

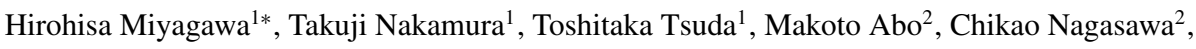 \\ Takuya D. Kawahara ${ }^{3}$, Keiji Kobayashi ${ }^{3 * *}$, Tsukasa Kitahara ${ }^{3}$, and Akio Nomura ${ }^{3}$ \\ ${ }^{1}$ Radio Atmospheric Science Center, Kyoto University, Uji, Kyoto, Japan \\ ${ }^{2}$ Graduate School of Electrical Engineering, Tokyo Metropolitan University, Hachioji, Tokyo, Japan \\ ${ }^{3}$ Faculty of Engineering, Shinshu University, Nagano, Japan
}

(Received August 17, 1998; Revised July 4, 1999; Accepted July 4, 1999)

\begin{abstract}
The dynamical structure of the atmosphere around the sporadic sodium layer at mid-latitude $\left(\sim 35^{\circ} \mathrm{N}\right)$ below 100 $\mathrm{km}$ was studied by simultaneous observation with the MU radar at Shigaraki $\left(34.9^{\circ} \mathrm{N}, 136.1^{\circ} \mathrm{E}\right)$, and two Na lidars at Shigaraki and in Hachioji $\left(35.6^{\circ} \mathrm{N}, 139.4^{\circ} \mathrm{E}\right)$. In the lidar data, fifteen $\mathrm{Na}_{\mathrm{s}}$ (sporadic sodium layer) events were detected. Wind shear, temperature, and stability indices, at around the time and height of $\mathrm{Na}_{\mathrm{s}}$ were observed with the MU radar. Strong total wind shear correlated well with $\mathrm{Na}_{\mathrm{s}}$, especially when sporadic Es did not accompany. However, no other clear correlations, such as correlations with temperature etc., were found. The result is similar to the report of the lidar observations in Hawaii during the ALOHA-93 campaign (Qian et al., 1998), and suggests a similar generation mechanism between $20^{\circ} \mathrm{N}$ and $35^{\circ} \mathrm{N}$.
\end{abstract}

\section{Introduction}

The vertical profiles of the mesospheric sodium layer, distributed at altitudes between about 80 and $110 \mathrm{~km}$, have been observed for more than 20 years by means of lidar techniques. During these observations, researchers discovered the sudden formation of a dense thin Na layer superposed on variations of mesospheric sodium layers. Such an enhanced layer is called a sporadic sodium layer $\left(\mathrm{Na}_{\mathrm{s}}\right)$ or a sudden sodium layer. $\mathrm{An} \mathrm{Na}_{\mathrm{s}}$ is characterized as a thin layer with a full-width at half maximum (FWHM) of 1-2 km, typically, lasting for a few tens of minutes to several hours. The ratio of peak $\mathrm{Na}$ density to the normal sodium density ranges typically from three to five, but occasionally is as large as ten (Nagasawa and Abo, 1995).

Clemesha et al. (1978) were the first to report observations of $\mathrm{Na}_{\mathrm{s}}$ layers which continued for three hours at São Paulo, Brazil $\left(23^{\circ} \mathrm{S}\right)$ in the late 1970 s. In the $1980 \mathrm{~s}$, many $\mathrm{Na}_{\mathrm{s}}$ events were observed at high latitudes at Andenes, Norway $\left(69^{\circ} \mathrm{N}\right)$ (von Zahn et al., 1987; von Zahn and Hansen, 1988), and Longyearbyen, Svalbard $\left(78^{\circ} \mathrm{N}\right)$ (Gardner et al., 1988), as well as at low latitude stations, such as Mauna Kea, Hawaii $\left(20^{\circ} \mathrm{N}\right)\left(\right.$ Kwon et al., 1988) and Arecibo, Puerto Rico $\left(18^{\circ} \mathrm{N}\right)$ (Beatty et al., 1989). However, at mid-latitudes, $\mathrm{Na}_{\mathrm{s}}$ were not observed despite the observation of normal sodium layers for long periods in Illinois $\left(40^{\circ} \mathrm{N}\right)($ Gardner et al., 1986) and Haute Provence, France $\left(44^{\circ} \mathrm{N}\right)$ (Granier and Megie, 1982). In the $1990 \mathrm{~s}$, the fairly frequent occurrence of $\mathrm{Na}_{\mathrm{s}}$ at mid-

\footnotetext{
* Now at Chubu Electric Power Company Inc., Nagoya, Japan.

**Now at Technical Research and Development Institute, Japan Defense Agency, Tokyo, Japan.

Copy right (C) The Society of Geomagnetism and Earth, Planetary and Space Sciences (SGEPSS); The Seismological Society of Japan; The Volcanological Society of Japan; The Geodetic Society of Japan; The Japanese Society for Planetary Sciences.
}

latitude at Hachioji, Japan $\left(35.6^{\circ} \mathrm{N}, 139.4^{\circ} \mathrm{E}\right)$ was reported by Nagasawa and Abo (1995), and the question arose as to the reason for such a big difference in the $\mathrm{Na}_{\mathrm{s}}$ occurrence at mid-latitudes.

Thus, $\mathrm{Na}_{\mathrm{s}}$ has been observed at low and high latitudes, as well as at limited mid-latitude stations, and various generation mechanisms have been proposed and discussed. As for high latitude observations, strong correlations between $\mathrm{Na}_{\mathrm{s}}$ and sporadic $\mathrm{E}$ (Es) occurrence have been observed, and mechanisms by which $\mathrm{Na}_{\mathrm{s}}$ is generated from the Es layer have been discussed (von Zahn et al., 1987; von Zahn and Hansen, 1988). They pointed out that the atomic $\mathrm{Na}$ generation by the high energy auroral particles from upper atmospheric smoke or dust particles concentrated on an Es occurrence is a possible mechanism for these high latitude $\mathrm{Na}_{\mathrm{s}}$. A very good correlation between Es and $\mathrm{Na}_{\mathrm{s}}$ was observed on low latitude observations using the incoherent scatter radar technique (Beatty et al., 1989; Kane et al., 1993). Based on such observations, the conversion of $\mathrm{Na}^{+}$ions, Na-bearing molecules, or smoke particles into neutral sodium atoms was discussed (e.g., Hansen and von Zahn, 1990; von Zahn and Murad, 1990). Kirkwood and von Zahn (1991) have suggested that a strong electric field generates Es and $\mathrm{Na}_{\mathrm{s}}$ layers in the auroral region. It is noteworthy that Nagasawa and Abo (1995) also pointed out the correlation between $\mathrm{Na}_{\mathrm{s}}$ and Es based on the observations at Hachioji at mid-latitude. More recently, Cox and Plane (1998) discussed the possibility of downward motion of Es as a source of $\mathrm{Na}_{\mathrm{s}}$ formation from $\mathrm{Na}^{+}$based on the results of laboratory experiments.

The possibility of neutral chemistry was also reported as a candidate for $\mathrm{Na}_{\mathrm{s}}$ generation. Zhou et al. (1993) argued that a temperature increase due to tides and/or gravity wave activity may produce the $\mathrm{Na}$ enhancement, since the sodium abun- 
dance is sensitive to temperature. The deposition of sodium from meteors was also discussed based on observations at Sao Jose dos Campos $\left(23^{\circ} \mathrm{S}, 46^{\circ} \mathrm{W}\right)$ (Clemesha et al., 1978 , 1980, 1988; Batista et al., 1989). Vertical displacement of the sodium layer to form $\mathrm{Na}_{\mathrm{s}}$ has also been considered as a possible cause (Clemesha et al., 1996).

Thus, $\mathrm{Na}_{\mathrm{s}}$ phenomena have been observed at different latitudes and various possibile sources have been discussed. However, little work has been done on the $\mathrm{Na}_{\mathrm{s}}$ at the midlatitude, which have been frequently observed in Hachioji, Japan $\left(35.6^{\circ} \mathrm{N}\right)($ Nagasawa and Abo, 1995), because of the lack of simultaneous campaign observations such as those ones carried out at high and low latitudes with radars and rocket observations.

The MU radar, an MST (mesosphere-stratosphere-troposphere) radar and an IS (incoherent scatter) radar using VHF frequency, located at Shigaraki $\left(34.9^{\circ} \mathrm{N}, 136.1^{\circ} \mathrm{W}\right)$, has been utilized to observe the dynamics of middle and upper atmospheres. Recently, the MU radar was used as a meteor radar (Nakamura et al., 1991), and the observation of the dynamical parameters such as wind and temperature fluctuations around the mesopause region has been carried out (Tsutsumi et al., 1996; Nakamura et al., 1997).

In this paper, the results of simultaneous observations with the MU radar and two sodium lidars, at Hachioji and Shigaraki, are used to elucidate the dynamical structure of the mesopause region on the occurrence of sporadic sodium layers at mid-latitude, in order to discuss the source of the $\mathrm{Na}_{\mathrm{s}}$ layers at this latitude. The observation of atmospheric waves in the mesospheric sodium layer with the MU radar and the sodium lidar at Hachioji has been reported by Namboothiri et al. (1996), and Kobayashi et al. (1999), but in this study we focus only on the $\mathrm{Na}_{\mathrm{s}}$ events.

\section{Observation}

\subsection{Meteor echo observation with the MU radar}

The MU (middle and upper atmosphere) radar is a monostatic pulse Doppler radar operated at 46.5 MHz VHF, constructed at Shigaraki, Shiga, Japan $\left(34.9^{\circ} \mathrm{N}, 136.1^{\circ} \mathrm{E}\right)$ in 1984 (Fukao et al., 1985a, b). The MU radar is characterized by an active phased array system with 475 Yagi antennas, and has been utilized for various middle atmospheric and upper atmospheric studies. This radar has been applied to meteor observations recently, in order to observe the mesosphere and lower thermosphere regions for 24 hours a day (Nakamura et al., 1991). The specific parameters of the meteor echo observation mode are summarized in Table 1. For the meteor mode observation, a transmitted pulse is phase modulated by a 16-bit complementary code with a $6 \mu$ s or $8 \mu$ s subpulse width. The inter-pulse period (IPP) is $1.95-2.56 \mathrm{msec}$. The received signal is coherently integrated for $4-8$ pulses. The decay rate of meteor echo power is calculated to obtain the diffusion coefficient. The doppler frequency shift is also determined from the phase progression of the meteor echo, from which the radial wind is estimated. We detect about 10,000 to 20,000 meteor echoes per day, and the observed radial wind and diffusion coefficient are accumulated in a time-height bin of 30 minutes $\times 1 \mathrm{~km}$. Then, the diffusion coefficient and horizontal wind velocities are estimated in each bin (Nakamura et al., 1997).
Table 1. Specifications of the MU radar meteor mode.

$\begin{array}{ll}\text { Location } & \text { Shigaraki }\left(34.9^{\circ} \mathrm{N}, 136.1^{\circ} \mathrm{E}\right) \\ \text { Transmitter } & \text { Circular array of } 475 \text { crossed Yagis } \\ \text { Operational frequency } & 46.5 \mathrm{MHz} \\ \text { Peak power } & 1 \mathrm{MW} \text { (maximum) } \\ \text { Average power } & 50 \mathrm{~kW} \\ \text { Pulse length } & 6-8 \mu \mathrm{sec} \\ \text { Code modulation } & 16 \mathrm{bit} \text { complementary code } \\ \text { Beam } & \text { all azimuth, elevation angle } 60^{\circ} / 45^{\circ} \\ \text { Receiver } & 3 \text { element Yagi } \times 4 \text { (interferometer) } \\ \text { Range resolution } & 900 \mathrm{~m} \\ \text { Sample range } & 76 \mathrm{~km}-248 \mathrm{~km} \\ \text { Wind velocity \& diffusion coefficient data } \\ \text { Height resolution } & 1 \mathrm{~km} \\ \text { Time resolution } & 30 \mathrm{minutes}\end{array}$

2.2 Lidar observations of the mesospheric sodium layer

In this study we employed two sodium density lidars; one at Tokyo Metropolitan University (TMU) in Hachioji $\left(35.6^{\circ} \mathrm{N}, 139.4^{\circ} \mathrm{E}\right)$ and the other at the MU radar observatory in Shigaraki $\left(34.9^{\circ} \mathrm{N}, 136.1^{\circ} \mathrm{E}\right)$. The former has been developed and operated by TMU and the latter by Shinshu University. The two lidars have a similar system diagram except for the energy source of the dye laser and the tuning system.

The TMU Na lidar system consists of a tunable dye laser, pumped by a frequency doubled Nd:YAG laser, a receiving telescope, a photomultiplier tube detector, a monitoring system for the transmitted laser wavelength, and a data acquisition system (Nagasawa and Abo, 1995). The data acquisition was performed by photon counting, with a sampling gate of $667 \mathrm{~ns}$, corresponding to a range resolution of $100 \mathrm{~m}$. A receiving Cassegrainian telescope with a primary mirror with a diameter of $28 \mathrm{~cm}$ (-October, 1992), $35 \mathrm{~cm}$ (October, 1992December, 1993), or $60 \mathrm{~cm}$ (December, 1993-) was used. The laser pulse repetition rate was $10 \mathrm{~Hz}$. The signals for 2000 laser shots were accumulated to obtain one profile every 4 minutes. Usually, two adjacent profiles were averaged in order to increase the signal to noise ratio, which made the time resolution 8 minutes.

Another Na lidar was installed at the Shigaraki MU observatory in September 1995 by Shinshu University. The basic system of this lidar was the same that used by Nomura et al. (1987), with a similar system design to the TMU Na lidar, except that the dye laser was excited by a coaxial flashlamp. As for the receiving system, a Shumidt-Cassegrainian telescope with a diameter of $35.5 \mathrm{~cm}$ was used. The laser pulse repetition rates were $0.2 \mathrm{~Hz}$ (-October, 1996) and $0.5 \mathrm{~Hz}$ (October, 1996-), respectively. The number of accumulations to obtain one profile were 100 (-August, 1996) and 300 (August, 1996-), respectively, with an effective sampling range of $750 \mathrm{~m}$.

The specifications of these lidars are summarized in Table 2, and the locations are displayed on the map in Fig. 1. The two observatories, Shigaraki and Hachioji, are $310 \mathrm{~km}$ 
Table 2. Specifications of the two sodium density lidars. The Hachioji Na lidar is operated by Tokyo Metropolitan University (TMU), while the Shigaraki Na lidar is operated by Shinshu University.

\begin{tabular}{|c|c|c|}
\hline \multirow[t]{3}{*}{ Location } & Hachioji & Shigaraki \\
\hline & (Tokyo Metropolitan Univ.) & (MU Observatory) \\
\hline & $35.6^{\circ} \mathrm{N}, 139.4^{\circ} \mathrm{E}$ & $34.9^{\circ} \mathrm{N}, 136.1^{\circ} \mathrm{E}$ \\
\hline \multicolumn{3}{|l|}{ Transmitter } \\
\hline \multirow[t]{2}{*}{ Laser } & Nd:YAG/SHG & Flashlamp \\
\hline & pumped DYE & pumped DYE \\
\hline \multirow[t]{2}{*}{ Linewidth (FWHM) } & $2.5 \mathrm{pm}$ & $3.0 \mathrm{pm}$ \\
\hline & & 10.0 pm (1996 Aug.-) \\
\hline Pulse energy & $100 \mathrm{~mJ}$ & $80-100 \mathrm{~mJ}$ \\
\hline \multirow[t]{2}{*}{ Repetition rate } & $10 \mathrm{~Hz}$ & $0.2 \mathrm{~Hz}$ \\
\hline & & $0.5 \mathrm{~Hz}$ (1996 Oct.-) \\
\hline Pulse length & $6 \mathrm{~ns}$ & $500 \mathrm{~ns}$ \\
\hline Beam divergence & $0.2 \mathrm{mrad}$ & $0.1 \mathrm{mrad}$ \\
\hline \multicolumn{3}{|l|}{ Receiver } \\
\hline \multirow[t]{3}{*}{ Telescope aperture } & $28 \mathrm{~cm}$ & $35 \mathrm{~cm}$ \\
\hline & $35 \mathrm{~cm}$ (1992 Oct.-) & \\
\hline & $60 \mathrm{~cm}(1993$ Dec.- $)$ & \\
\hline Field of view & $0.7 \mathrm{mrad}$ & $1 \sim 3 \mathrm{mrad}$ \\
\hline Optical bandwidth & $3.5 \mathrm{~nm}(\mathrm{FWHM})$ & $1.0 \mathrm{~nm}(\mathrm{FWHM})$ \\
\hline \multicolumn{3}{|l|}{ Data acquisition } \\
\hline Type & Photon counting & Photon counting \\
\hline Range resolution & $100 \mathrm{~m}$ & $750 \mathrm{~m}$ \\
\hline Time resolution & 8 minutes & 10 minutes \\
\hline \multirow[t]{2}{*}{ Accumulation } & 4000 shots & 100 shots \\
\hline & & 300 shots (1996 Oct.-) \\
\hline
\end{tabular}



Fig. 1. Locations of the observatories and observation equipment. At Shigaraki, the MU radar and a sodium density lidar are operated by Radio Atmospheric Science Center (RASC), Kyoto University, and Shinshu University, respectively. At Hachioji, a sodium density lidar is operated by Tokyo Metropolitan University (TMU). apart, and the baseline between the sites is approximately zonally aligned.

\subsection{Overview of simultaneous observations}

Simultaneous observations of the mesopause region have been carried out with the MU radar and TMU Na lidar since August, 1992, and with the Shigaraki Na lidar since November, 1995. The numbers of simultaneous observations are summarized in Table 3.

Meteor observations with the MU radar are performed on a campaign basis, each observation being usually carried out for a few to ten days. During meteor shower periods in August and November, annual observations have been regularly carried out, while a number of campaigns with optical instruments such as lidars, airglow photometers and imagers have been carried out recently since 1995 .

During the MU radar meteor mode observations, Na lidars observed $\mathrm{Na}$ density profiles at Hachioji and Shigaraki, although these optical observations were sometimes prevented by cloudy weather conditions, which resulted in a smaller total number of observation days. Between August 1992 and 
Table 3. Numbers of observations in a month for the MU radar and sodium lidars. The former correspond to the nights of meteor mode observations, and the latter to the nights of simultaneous observations with the MU radar.

\begin{tabular}{|c|c|c|c|c|c|}
\hline \multirow[b]{2}{*}{ Year } & \multirow[b]{2}{*}{ Month } & \multirow{2}{*}{$\begin{array}{l}\text { MU Radar Obs. } \\
\text { (Meteor mode) } \\
\text { (nights) }\end{array}$} & \multicolumn{3}{|c|}{ Na lidar, simultaneously } \\
\hline & & & $\begin{array}{l}\text { Hachioji } \\
\text { (nights) }\end{array}$ & $\begin{array}{l}\text { Shigaraki } \\
\text { (nights) }\end{array}$ & $\begin{array}{l}\text { (Both) } \\
\text { (nights) }\end{array}$ \\
\hline 1992 & AUG & 9 & 1 & - & - \\
\hline \multirow[t]{4}{*}{1993} & JAN & 4 & 2 & - & - \\
\hline & APR & 4 & 2 & - & - \\
\hline & AUG & 3 & 2 & - & - \\
\hline & $\mathrm{DEC}$ & 3 & 2 & - & - \\
\hline 1994 & NOV & 8 & 2 & - & - \\
\hline \multirow[t]{5}{*}{1995} & JUL & 6 & 3 & - & - \\
\hline & AUG & 3 & 1 & - & - \\
\hline & SEP & 5 & 2 & - & - \\
\hline & NOV & 9 & 4 & 3 & 1 \\
\hline & $\mathrm{DEC}$ & 5 & 2 & 3 & 1 \\
\hline \multirow[t]{5}{*}{1996} & APR & 2 & 1 & 0 & 0 \\
\hline & AUG & 5 & 1 & 3 & 0 \\
\hline & OCT & 4 & 2 & 3 & 1 \\
\hline & NOV & 7 & 3 & 4 & 3 \\
\hline & DEC & 4 & 2 & 0 & 0 \\
\hline 1997 & JAN & 10 & 6 & 7 & 4 \\
\hline \multicolumn{2}{|c|}{ Total } & 91 & 38 & 23 & 10 \\
\hline
\end{tabular}

January 1997, simultaneous observations with the MU radar were successfully carried out on 38 and 23 nights with the Hachioji and Shigaraki Na lidars, respectively. Simultaneous observations with all three (the MU radar, and two lidars) have been made on 10 nights.

\section{Data Analysis}

\subsection{Analysis of dynamical parameters with the MU radar data}

From meteor echo observations with the MU radar, the horizontal wind velocity and diffusion coefficient are obtained with time and height resolutions of 30 minutes and $1 \mathrm{~km}$, respectively, between 75 and $100 \mathrm{~km}$ (Nakamura et al., 1997). The relative temperature fluctuation is also estimated from the diffusion coefficient by applying a Boussinesq approximation (Tsutsumi et al., 1996). In this study, we further derive the vertical gradients of the obtained parameters, such as the wind shear and vertical temperature gradients, and then the indices of the atmospheric stability such as The BruntVäisälä frequency, $N$, and Richardson number, $R i$, are also calculated.

We estimate horizontal winds, $u(z, t)$ or $v(z, t)$, at altitude $z(\mathrm{~km})$ with a height interval of $1 \mathrm{~km}$. Therefore, we can calculate wind shear by taking the difference between the horizontal (zonal or meridional) wind velocities of two neighboring heights in the profile. However, the differentiation shown here will increase the error in wind shear estimation. In order to avoid this, the results are smoothed to have an effective time and height resolution of $2 \mathrm{~km} \times 1$ hour. In addition to the wind shear of zonal and meridional wind velocities, the total wind shear,

$$
\sqrt{\left(\frac{d u}{d z}\right)^{2}+\left(\frac{d v}{d z}\right)^{2}}
$$

is also calculated with the same time and height resolutions.

The temporal fluctuation of the relative temperature, $T^{\prime} / T_{0}$ (o denotes the time average), is determined from the ambipolar diffusion coefficient, $D$, obtained by means of the decay time constant of radar meteor echoes. However, in order to estimate the vertical temperature gradient, which is significantly perturbed by the atmospheric wave activity, we have to determine absolute temperature, $T$, for each time and height bin in the meteor observations. In this study, we assume that the profile of time-averaged temperature, $T_{0}$, is identical to the model description in CIRA 1986 (COSPAR International Reference Atmosphere), and then the absolute temperature, $T$, and fluctuation, $T^{\prime}$, are estimated in each time-height bin of 30 minutes $\times 1 \mathrm{~km}$.

From the estimated temperatures, we also calculate the Brunt-Väisälä frequency squared, $N^{2}$, which is expressed as

$$
N^{2}=\frac{g_{0}}{T}\left(\frac{d T}{d z}+\frac{g_{0}}{C_{p}}\right)
$$

where $g_{0}$ and $C_{p}$ are gravitational acceleration and specific heat at constant pressure, respectively. $N^{2}$ is also estimated with a time-height resolution of 1 hour $\times 2 \mathrm{~km}$, in order to reduce the estimation error. Then, the Richardson number, $R i$, which indicates atmospheric stability by wind shears, can be calculated as follows,

$$
R i=\frac{N^{2}}{\left(\frac{d u}{d z}\right)^{2}+\left(\frac{d v}{d z}\right)^{2}} .
$$

The histograms in Fig. 2 present the distributions of zonal (a), meridional (b) and total (c) shears for the altitude range of all data, i.e., between $75 \mathrm{~km}$ and $110 \mathrm{~km}$ in August 1995 . Zonal and meridional shears can be approximated by a Gaussian distribution with a mean value close to zero and standard deviation of each wind shear of $7.0 \mathrm{~m} / \mathrm{s} / \mathrm{km}$ and $7.8 \mathrm{~m} / \mathrm{s} / \mathrm{km}$, respectively, while the total shear shows a distribution similar to a $\chi^{2}$-distribution with a mean value of $9.0 \mathrm{~m} / \mathrm{s} / \mathrm{km}$.

The distribution of temperature fluctuation, $T^{\prime}$, is plotted in Fig. 2(d). The standard deviation of $T^{\prime}$ (i.e., r.m.s. amplitude) is $15 \mathrm{~K}$. Although the $T^{\prime}$ distribution can be approximated well by the Gaussian distribution, negative $T^{\prime}$ values appear slightly more frequently. The distribution of the Brunt-Väisälä frequency squared, $N^{2}$, is plotted in Fig. 2(e) with a Gaussian function as dotted lines. The shaded area indicates the region of convective instability. $N^{2}$ also seems to be approximated by a Gaussian distribution as $T^{\prime}$. The mean value of $N^{2}$ in this month is $4.9 \times 10^{-4}(\mathrm{rad} / \mathrm{sec})^{2}$, corresponding to 4.7 minutes in oscillation period. The standard deviation is $3.1 \times 10^{-4}$, indicating that at most times and heights, $N$ is distributed between 3.7 and 7.7 minutes. 

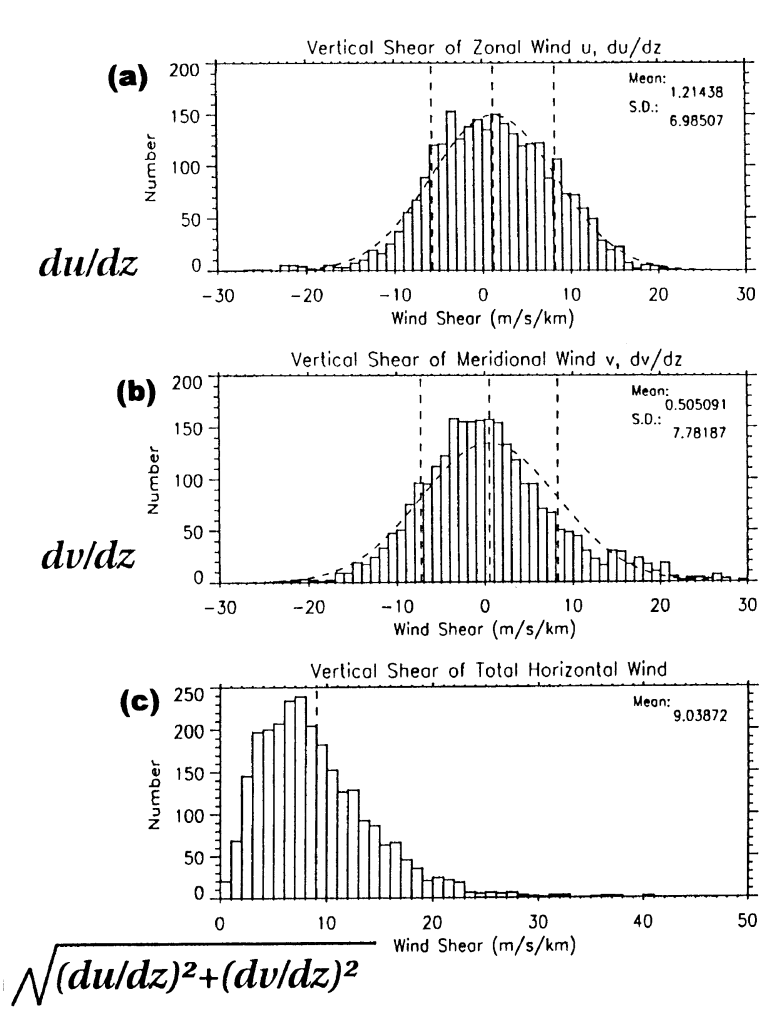
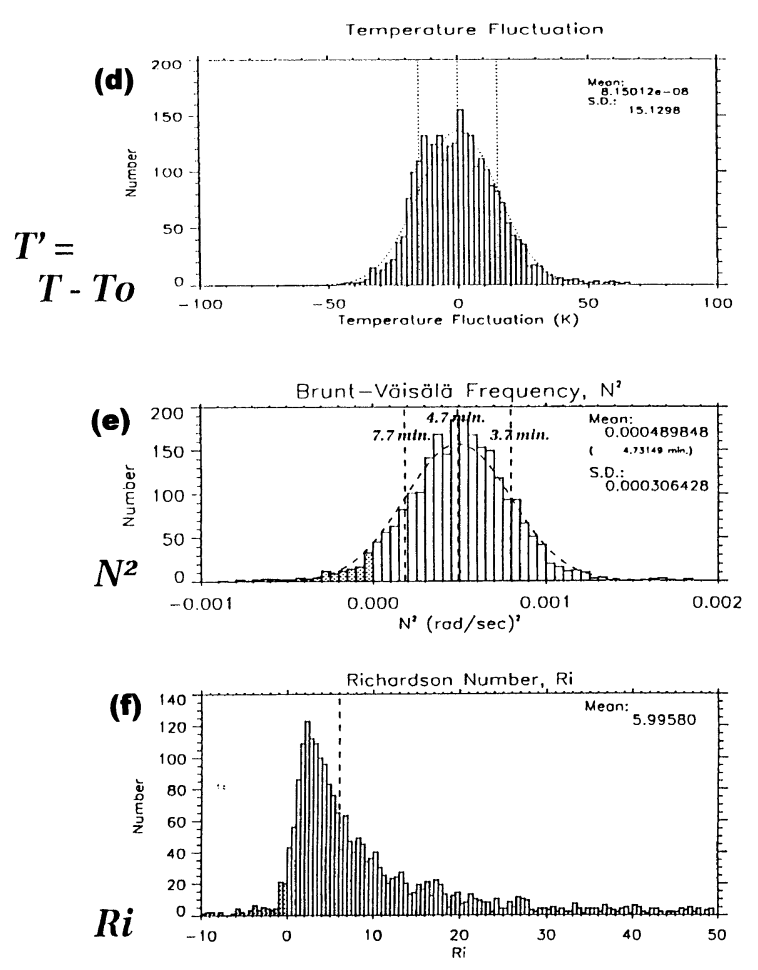

Fig. 2. Distributions of estimated atmospheric parameters observed with the MU radar. Each histogram presents the distribution of wind shears ((a) zonal $(\mathrm{d} u / \mathrm{d} z),(\mathrm{b})$ meridional (d $v / \mathrm{d} z)$ and (c) total), (d) temperature fluctuation, $T^{\prime}$, (e) Brunt-Väisälä frequency squared, $N^{2}$, and (f) Richardson number, $R i$, in August 1995 in the altitude range of $75-100 \mathrm{~km}$.

Such statistics are obtained every month and used to determine whether the dynamical parameters at $\mathrm{Na}_{\mathrm{s}}$ events are common or significantly strong (or weak).

It should be noted that the MU radar observatory at Shigaraki and the TMU lidar observatory at Hachioji are located about $310 \mathrm{~km}$ apart. Thus, the atmospheric parameters observed at Shigaraki are not always the same as those above Hachioji, precisely. However, the atmospheric parameters observed with the MU radar are average values over $200 \mathrm{~km}$ in horizontal extent, and are affected mainly by inertia gravity waves with horizontal wavelengths of larger than $500 \mathrm{~km}$, global scale tides, planetary waves and mean winds. Hodograph analyses of the inertia gravity waves seen here revealed that the phase difference of these inertia gravity waves at Shigaraki at the times of the $\mathrm{Na}_{\mathrm{s}}$ events shown here are mainly propagated in the meridional direction rather than in the zonal direction, and hence the phase difference between Shigaraki and Hachioji is usually as small as within 30 min1 hours. It is also noteworthy that the wind and temperature caused by atmospheric tides, which have a large amplitude at this altitude, exhibit a phase difference of only about 13 minutes. Thus, in this study we consider that the background atmospheric parameters for Shigaraki and Hachioji are basically the same with no time lag.

\subsection{Analysis of sodium density structure}

Although many studies on $\mathrm{Na}_{\mathrm{s}}$ have been performed since Clemesha et al. (1978) reported $\mathrm{Na}_{\mathrm{s}}$ events for the first time at São Paulo, Brazil, the definition of $\mathrm{Na}_{\mathrm{s}}$ is not clear, and is sometimes subjective. In order to avoid this uncertainty, we first describe a more objective method to select $\mathrm{Na}_{\mathrm{s}}$ event, and applied to the sodium density data in this study. The criteria are:

1) To find an enhancement of $\mathrm{Na}$ density as a candidate $\mathrm{Na}_{\mathrm{s}}$ event.

2) To calculate the full width of half maximum (FWHM) thickness of the layer for each enhancement event, and further select candidates with a FWHM thickness of smaller than $5 \mathrm{~km}$.

3) To calculate the ratio of the maximum density at the enhancement to the normal density at the same altitude. The normal density is estimated with the following algorithm, which is the same one as that used by Nagasawa and Abo (1995). The concept is illustrated in Fig. 3.

(a) To determine the peak density, $\rho_{p}$, and the corresponding height, $H_{p}$, of a candidate $\mathrm{Na}_{\mathrm{s}}$.

(b) To detect the upper and lower heights, $H_{u h}$ and $H_{l h}$, where $\mathrm{Na}$ density becomes half the maximum, i.e., $\rho_{p} / 2$. If there are more than two $H_{u h}$ or $H_{l h}$, choose the nearest one to $H_{p}$.

(c) Estimate the altitudes of the upper and lower ends, $H_{u e}$ and $H_{l e}$, of the candidate as follows

$$
\begin{gathered}
H_{u e}=H_{p}+2\left(H_{u h}-H_{p}\right), \\
H_{l e}=H_{p}-2\left(H_{p}-H_{l h}\right) .
\end{gathered}
$$




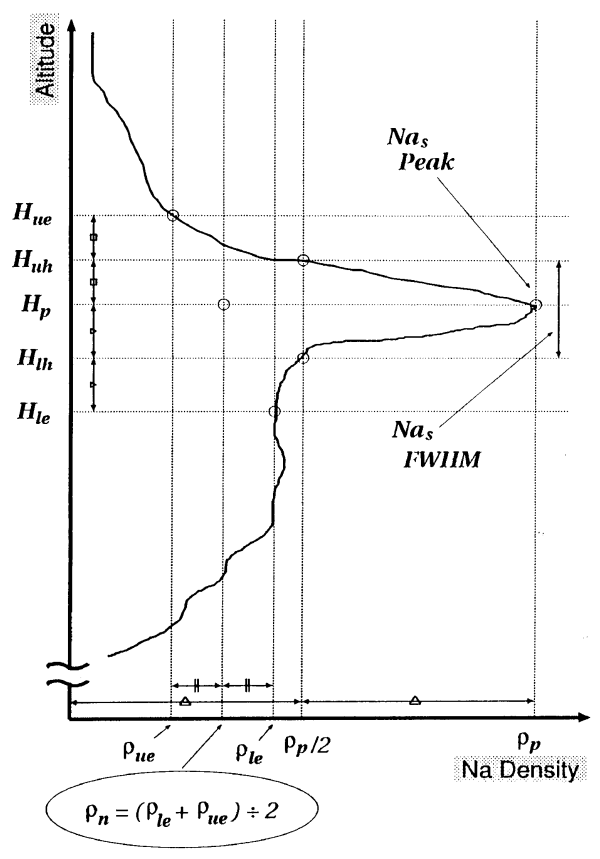

Fig. 3. The concept of FWHM of $\mathrm{Na}_{\mathrm{S}}$ and estimation of the density of the normal $\mathrm{Na}$ layer (see text for details).

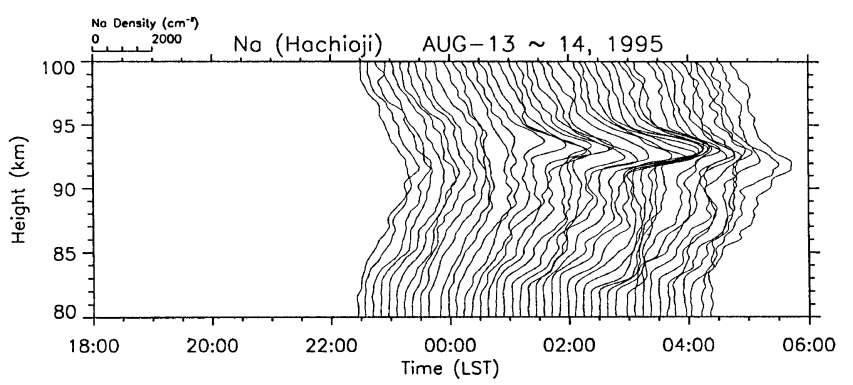

Fig. 4. An example of $\mathrm{Na}$ density profiles observed with the Hachioji Na lidar on August 13/14, 1995.

(d) To determine the Na density, $\rho_{u e}$ and $\rho_{l e}$, at $H_{u e}$ and $H_{l e}$.

(e) The density of the normal Na layer, $\rho_{n}$, at $H_{p}$ is calculated as

$$
\rho_{n}=\frac{\rho_{u e}+\rho_{l e}}{2} .
$$

The ratio of the maximum $\mathrm{Na}$ density to that of the normal layer is defined as $\rho_{p} / \rho_{n}$. If this ratio is greater than two, the event is judged to be an $\mathrm{Na}_{\mathrm{s}}$ event.

Figure 4 shows the profiles of an $\mathrm{Na}_{\mathrm{s}}$ event detected by applying the above procedure, on August 13/14, 1995, at Hachioji. During this night the background structure of the sodium layer profile did not change significantly, and fluctuations with downward or upward phase propagations associated with atmospheric waves were not clearly observed. Starting at 0:30 LST $(=$ JST $=\mathrm{UT}+9)$, a significant $\mathrm{Na}_{\mathrm{s}}$ event appeared at $93 \mathrm{~km}$, and continued for about 3 hours, with the peak moving downward slightly for about one hour, and then slowly upward at a speed of about $1 \mathrm{~km} /$ hour. At 1:57 LST, the peak $\mathrm{Na}_{\mathrm{s}}$ density reached a maximum at 92.8 $\mathrm{km}$, the ratio of the $\mathrm{Na}_{\mathrm{s}}$ maximum to the normal layer being 2.8 .

\section{Results}

\section{1 $\mathrm{Na}_{\mathrm{s}}$ events}

$\mathrm{Na}_{\mathrm{s}}$ events are selected according to the criteria described in the previous section, and eleven and four $\mathrm{Na}_{\mathrm{s}}$ events were detected at Hachioji and Shigaraki, respectively, during the simultaneous observation period. The characteristics of the $\mathrm{Na}_{\mathrm{s}}$ events are summarized in Table 4, and also in Fig. 5.

Figure 5(a) shows the distribution of $\mathrm{Na}_{\mathrm{s}}$ duration. Most of the events continued for a few tens of minutes to one hour. However, three events at Hachioji and one at Shigaraki continued for more than two hours. The mean value and standard deviation of the $\mathrm{Na}_{\mathrm{s}}$ duration are 74 and 46 minutes, respectively. Nagasawa and Abo (1995) reported the statistics for $\mathrm{Na}_{\mathrm{s}}$ based on observations with the same lidar system but for a larger database of $37 \mathrm{Na}_{\mathrm{s}}$ events observed in 1991-1993 at Hachioji, and showed that the mean value and standard deviation of the $\mathrm{Na}_{\mathrm{s}}$ duration are 110 minutes and 63 minutes, respectively, which are slightly larger but not significantly different from our results.

The distribution of $\mathrm{Na}_{\mathrm{s}}$ altitude at the maximum $\mathrm{Na}$ density is plotted in Fig. 5(b). $\mathrm{Na}_{\mathrm{s}}$ events seem to be classifiable into two types according to the peak altitude; i.e. between about 91 and $97 \mathrm{~km}$ altitude with a mean at about $94 \mathrm{~km}$, and above $99 \mathrm{~km}$.

The distribution of FWHM of the $\mathrm{Na}_{\mathrm{s}}$ layer, shown in Fig. 5(c), indicates that a thickness of 3 to $4 \mathrm{~km}$ is commonly seen, although it should be noted that with our criteria the maximum FWHM is limited to $5 \mathrm{~km}$. The FWHM of $\mathrm{Na}_{\mathrm{s}}$ observed here is slightly broader than in other studies, such as those of Nagasawa and Abo (1995) and Qian et al. (1998), in which 1-3 km was typical. It should be noted that Nagasawa and Abo (1995) calculated the FWHM only for $\mathrm{Na}_{\mathrm{s}}$ density after subtracting the normal $\mathrm{Na}$ layer, however, in the current analysis the FWHM is determined for the total $\mathrm{Na}$ density, and therefore this difference in the analysis could cause the FWHM values in Fig. 5 to be slightly larger than those of Nagasawa and Abo (1995).

The ratio of the peak $\mathrm{Na}$ density at $\mathrm{Na}_{\mathrm{s}}$ to the normal density of the Na layer is plotted in Fig. 5(d), which shows 3-4 is typical, and that is sometimes becomes larger than 5. This tendency is similar to the previous observations at Hachioji (Nagasawa and Abo, 1995) and Hawaii in the ALOHA/ANLC-93 campaign (Qian et al., 1998).

Thus, in general the observed characteristics of the $\mathrm{Na}_{\mathrm{S}}$ layer shown in Table 4 and Fig. 5 are similar to those reported by Nagasawa and Abo, (1995), which suggests our criteria for $\mathrm{Na}_{\mathrm{s}}$ recognition shown in the previous section work reasonably well.

Nagasawa and Abo (1995) indicated a strong correlation of $\mathrm{Na}_{\mathrm{s}}$ with Es occurrences. The existence of Es around the time of each $\mathrm{Na}_{\mathrm{s}}$ event observed at Shigaraki and Hachioji by means of ionosondes is also displayed in Table 4. Eight of the 15 events were accompanied by Es, mainly in the summer, with one event in January. 
Table 4. Detected $\mathrm{Na}_{\mathrm{s}}$ events, and summary of the results of correlation analysis between $\mathrm{Na}_{\mathrm{s}}$ occasions and the dynamical structures of the atmosphere.

Hachioji $\left(35.6^{\circ} \mathrm{N}, 139.4^{\circ} \mathrm{E}\right)$

\begin{tabular}{|c|c|c|c|c|c|c|c|c|}
\hline \multirow{2}{*}{$\begin{array}{l}\text { Observation } \\
\text { date } \\
\text { (DMY) }\end{array}$} & \multirow{2}{*}{$\begin{array}{c}\mathrm{Na}_{s} \\
\text { period } \\
(\mathrm{LST})\end{array}$} & \multirow{2}{*}{$\begin{array}{l}\text { Duration } \\
\text { (minutes) }\end{array}$} & \multicolumn{5}{|c|}{ At the peak density } & \multirow[b]{2}{*}{ Es } \\
\hline & & & $\begin{array}{l}\text { Time } \\
(\mathrm{LST})\end{array}$ & $\begin{array}{l}\text { Height } \\
(\mathrm{km})\end{array}$ & $\begin{array}{l}\text { FWHM } \\
\qquad(\mathrm{km})\end{array}$ & $\begin{array}{c}\text { Density } \\
\left(10^{3} \mathrm{~cm}^{-3}\right)\end{array}$ & $\begin{array}{c}\text { Density } \\
\text { ratio }\end{array}$ & \\
\hline 06/07-AUG-1992 & $19: 56-20: 22$ & 26 & 20:09 & 95.5 & 3.5 & 2.2 & 3.7 & $\mathrm{Y}$ \\
\hline 06/07-AUG-1992 & $21: 33-21: 57$ & 24 & $21: 39$ & 99.3 & 3.5 & 1.7 & 3.3 & $\mathrm{~N}$ \\
\hline 28/29-JAN-1993 & $23: 44-0: 47$ & 63 & 00:03 & 93.9 & 1.9 & 3.0 & 2.7 & $\mathrm{~N}$ \\
\hline 24/25-JUL-1995 & $20: 14-20: 38$ & 16 & $20: 26$ & 91.9 & 1.9 & 2.7 & 3.3 & $\mathrm{Y}$ \\
\hline 24/25-JUL-1995 & $22: 38-23: 25$ & 47 & $23: 22$ & 96.5 & 3.4 & 2.0 & 3.5 & $\mathrm{Y}$ \\
\hline 26/27-JUL-1995 & $19: 46-20: 51$ & 65 & $20: 12$ & 95.5 & 3.0 & 2.5 & 3.7 & $\mathrm{Y}$ \\
\hline 26/27-JUL-1995 & $23: 29-0: 16$ & 47 & $23: 41$ & 93.9 & 1.6 & 3.9 & 5.4 & $\mathrm{Y}$ \\
\hline 13/14-AUG-1995 & $0: 18-2: 49$ & 151 & $01: 57$ & 92.8 & 3.1 & 4.4 & 2.8 & $\mathrm{~N}$ \\
\hline 20/21-SEP-1995 & $19: 57-21: 14$ & 77 & $20: 27$ & 94.4 & 2.3 & 4.7 & 3.2 & $\mathrm{~N}$ \\
\hline 22/23-APR-1996 & 22:04-0:06 & 122 & $23: 31$ & 93.4 & 2.4 & 1.6 & 3.5 & $\mathrm{~N}$ \\
\hline 11/12-JAN-1997 & $23: 05-1: 10$ & 127 & $23: 31$ & 96.9 & 1.8 & 4.9 & 4.3 & $\mathrm{Y}$ \\
\hline
\end{tabular}

Shigaraki $\left(34.9^{\circ} \mathrm{N}, 136.1^{\circ} \mathrm{E}\right)$

\begin{tabular}{|c|c|c|c|c|c|c|c|c|}
\hline \multirow{2}{*}{$\begin{array}{l}\text { Observation } \\
\text { date } \\
\text { (DMY) }\end{array}$} & \multirow{2}{*}{$\begin{array}{c}\mathrm{Na}_{s} \\
\text { period } \\
(\mathrm{LST})\end{array}$} & \multirow{2}{*}{$\begin{array}{l}\text { Duration } \\
\text { (minutes) }\end{array}$} & \multicolumn{5}{|c|}{ At the peak density } & \multirow[b]{2}{*}{ Es } \\
\hline & & & $\begin{array}{l}\text { Time } \\
\text { (LST) }\end{array}$ & $\begin{array}{l}\text { Height } \\
(\mathrm{km})\end{array}$ & $\begin{array}{l}\text { FWHM } \\
\qquad(\mathrm{km})\end{array}$ & $\begin{array}{c}\text { Density } \\
\left(10^{3} \mathrm{~cm}^{-3}\right)\end{array}$ & $\begin{array}{c}\text { Density } \\
\text { ratio }\end{array}$ & \\
\hline 23/24-DEC-1995 & $22: 18-22: 45$ & 27 & $22: 18$ & 92.6 & 3.8 & 9.1 & 3.2 & $\mathrm{~N}$ \\
\hline 11/12-AUG-1996 & $21: 28-22: 13$ & 45 & $21: 55$ & 99.4 & 3.0 & 8.0 & 3.2 & $\mathrm{Y}$ \\
\hline 11/12-AUG-1996 & $23: 12-1: 24$ & 132 & $0: 31$ & 93.4 & 4.5 & 10.5 & 5.6 & $\mathrm{Y}$ \\
\hline 15/16-NOV-1996 & $21: 56-22: 17$ & 21 & $21: 56$ & 91.1 & 3.8 & 7.3 & 3.5 & $\mathrm{~N}$ \\
\hline
\end{tabular}

\begin{tabular}{|c|c|c|c|c|c|c|c|}
\hline \multicolumn{4}{|c|}{ Vertical shear of horizontal wind } & \multicolumn{2}{|c|}{ Temperature } & \multirow{2}{*}{$\begin{array}{c}\text { Brunt-Väisälä } \\
\text { Frequency, } N^{2} \\
\left(\times 10^{-4} \mathrm{rad} / \mathrm{sec}\right)^{2}\end{array}$} & \multirow{2}{*}{$\begin{array}{l}\text { Richardson } \\
\text { Number, } R i\end{array}$} \\
\hline $\begin{array}{c}\text { Zonal } \\
(\mathrm{m} / \mathrm{s} / \mathrm{km})\end{array}$ & $\begin{array}{l}\text { Meridional } \\
(\mathrm{m} / \mathrm{s} / \mathrm{km})\end{array}$ & $\begin{array}{c}\text { Total } \\
(\mathrm{m} / \mathrm{s} / \mathrm{km})\end{array}$ & $\begin{array}{c}\text { Direction } \\
\left(\text { Azimuth, }{ }^{\circ}\right)\end{array}$ & $\begin{array}{c}T^{\prime} \\
(\mathrm{K}) \\
\end{array}$ & $\begin{array}{c}T \\
(\mathrm{~K}) \\
\end{array}$ & & \\
\hline+9.2 & -3.9 & 10.0 & +113 & -10 & 169 & 3.21 & 3.58 \\
\hline+5.2 & -14.8 & 15.7 & +161 & - & - & - & - \\
\hline-5.3 & -20.9 & 21.6 & -166 & +16 & 206 & 2.52 & 0.54 \\
\hline-17.7 & -3.4 & 18.1 & -100 & -20 & 148 & 5.56 & 1.70 \\
\hline+2.2 & +1.0 & 2.4 & +65 & +15 & 195 & 5.77 & 164 \\
\hline+2.7 & +2.5 & 3.7 & +48 & -1 & 179 & 7.03 & 50.8 \\
\hline-2.9 & +9.0 & 9.4 & -18 & -20 & 153 & 9.96 & 11.2 \\
\hline+15.6 & -16.1 & 22.4 & +136 & +29 & 201 & 6.13 & 1.22 \\
\hline-13.6 & +5.4 & 14.7 & -69 & +2 & 178 & 2.34 & 1.09 \\
\hline-14.8 & +18.3 & 23.5 & -39 & -19 & 158 & 5.43 & 2.86 \\
\hline+9.6 & -10.1 & 13.9 & +137 & -23 & 168 & 3.02 & 1.56 \\
\hline \multicolumn{4}{|c|}{ Vertical shear of horizontal wind } & \multicolumn{2}{|c|}{ Temperature } & Brunt-Väisälä & Richardson \\
\hline Zonal & Meridional & Total & Direction & $T^{\prime}$ & $T$ & Frequency, $N^{2}$ & Number, $R i$ \\
\hline$(\mathrm{m} / \mathrm{s} / \mathrm{km})$ & $(\mathrm{m} / \mathrm{s} / \mathrm{km})$ & $(\mathrm{m} / \mathrm{s} / \mathrm{km})$ & & & & $\left(\times 10^{-4} \mathrm{rad} / \mathrm{sec}\right)^{2}$ & \\
\hline-2.8 & +14.2 & +14.5 & -11 & -17 & 176 & 5.47 & 14.0 \\
\hline - & - & - & - & - & - & - & - \\
\hline+1.7 & +7.7 & +7.9 & +13 & +8 & 180 & 3.67 & 1.7 \\
\hline-25.5 & -3.6 & +25.8 & -98 & -2 & 188 & 4.64 & 23.2 \\
\hline
\end{tabular}




\section{Nas Characteristics}
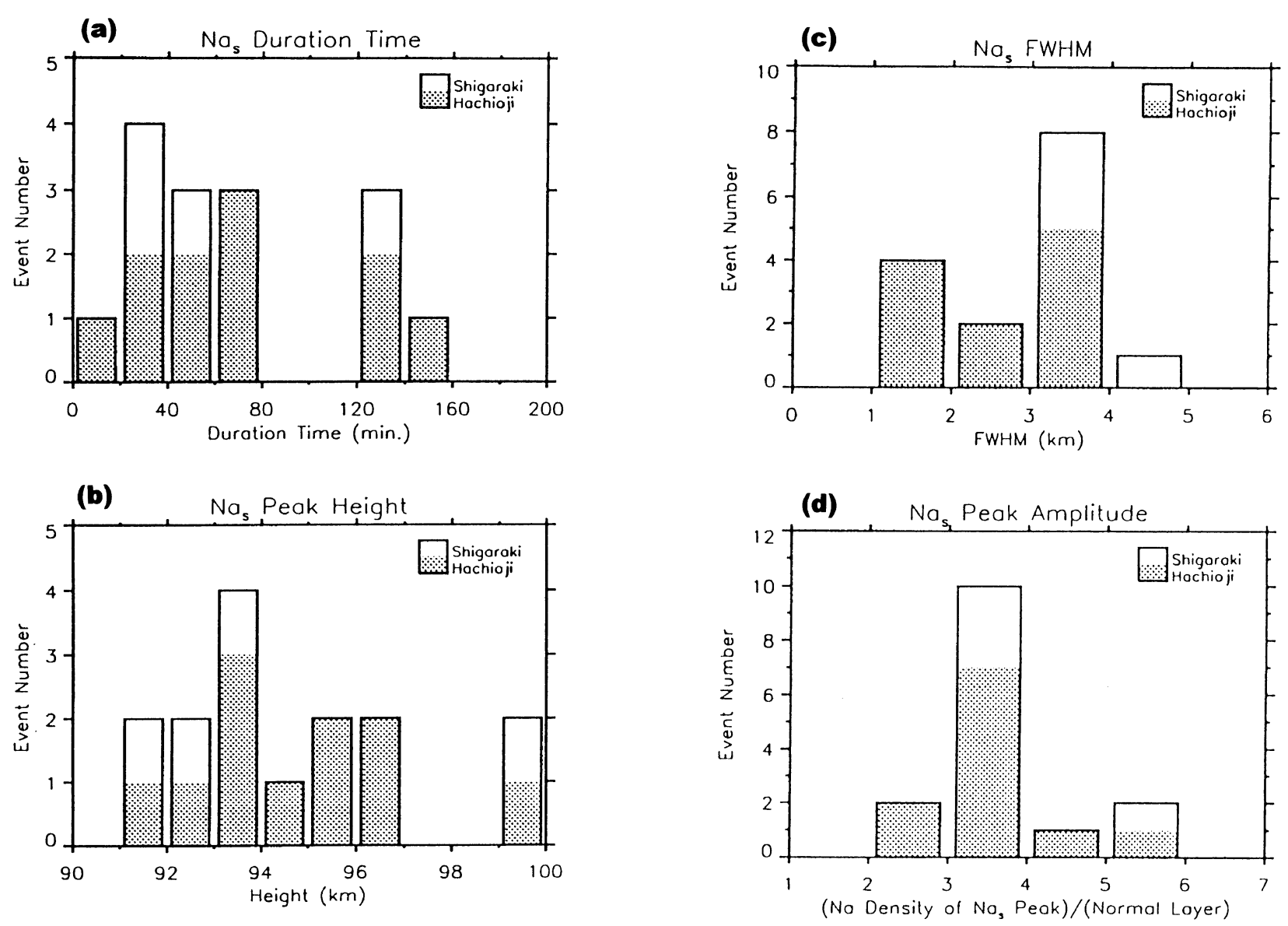

Fig. 5. Distributions of $\mathrm{Na}_{\mathrm{s}}$ characteristics. The histograms present (a) $\mathrm{Na}_{\mathrm{s}}$ duration time, (b) height, (c) FWHM, and (d) amplitude at the Na density maximum. The open and shaded boxes correspond to the events observed at Shigaraki and Hachioji, respectively.

\subsection{Simultaneous observations: case studies}

The first two panels in Fig. 6 present the profiles and a contour plot of the sodium density between 18:00 LST and 06:00 LST on September 20/21, 1995, observed with the TMU Na lidar at Hachioji. The other panels in the same figure show the zonal and meridional wind velocities, and their vertical shear, temperature fluctuations, Brunt-Väisälä frequencies, and Richardson numbers, observed simultaneously with the MU radar at Shigaraki. During the observation period on this night, a normal Na layer moved downward from $94 \mathrm{~km}$ at 19:00 LST to $90 \mathrm{~km}$ at 21:00 LST, with a vertical speed of about $2 \mathrm{~km} /$ hour. A strong $\mathrm{Na}_{\mathrm{s}}$ event started at 19:57 LST at about $95 \mathrm{~km}$ altitude and the density reached the maximum at 20:27 LST at $94.4 \mathrm{~km}$ altitude, decreasing slowly afterwards. This $\mathrm{Na}_{\mathrm{s}}$ event continued at least until 21:14 LST when the lidar observation was interrupted, with a downward motion with a velocity of about $1 \mathrm{~km} /$ hour. It is noteworthy that the downward velocity of the $\mathrm{Na}_{\mathrm{s}}$ was smaller than that of the normal $\mathrm{Na}$ layer. During the $\mathrm{Na}_{\mathrm{s}}$ event, strong westward shear of the zonal wind was observed between 19:30 and 21:00 LST and between 94 and $95 \mathrm{~km}$ altitude, which is about the time and altitude of the $\mathrm{Na}_{\mathrm{s}}$ occurrence. The ionosondes at both Shigaraki and Kokubunji (near Hachioji) did not detect a sporadic E layer around the time of this event.

The wind velocities, $u$ and $v$, showed strong oscillation with a period of around 12 hours, especially above $90 \mathrm{~km}$, which is probably a semidiurnal tide or an inertia gravity wave. The peak amplitude reached $60 \mathrm{~m} / \mathrm{s}$, and the downward phase progression suggests an upward energy propagating wave. Accordingly, the wind shears, $\mathrm{d} u / \mathrm{d} z$ and $\mathrm{d} v / \mathrm{d} z$, showed similar downward phase progression, but the vertical scale was shorter and exhibited a shorter period component superposed on the 12 hours variation, suggesting multiple waves were propagating at the same time. At 20:30 LST and $94 \mathrm{~km}$ altitude, when and where the $\mathrm{Na}$ density of the $\mathrm{Na}_{\mathrm{s}}$ layer became maximum, the intensity of the zonal wind shear, $\mathrm{d} u / \mathrm{d} z$, was $-13.6 \mathrm{~m} / \mathrm{s} / \mathrm{km}$. The standard deviation of the zonal shear, i.e., the r.m.s. amplitude observed in this month, was $6.8 \mathrm{~m} / \mathrm{s} / \mathrm{km}$. Thus, the westward shear observed here was significantly large compared with the statistical fluctuation of the zonal shear. $\mathrm{d} u / \mathrm{d} z$ reached its maximum of $-19.6 \mathrm{~m} / \mathrm{s} / \mathrm{km}$ at 20:00 LST and $95 \mathrm{~km}$ altitude, which preceded the time of the $\mathrm{Na}_{\mathrm{s}}$ density maximum by 30 minutes and $1 \mathrm{~km}$ above the $\mathrm{Na}_{\mathrm{s}}$ layer. On the other hand, $\mathrm{d} v / \mathrm{d} z$ at the $\mathrm{Na}_{\mathrm{s}}$ maximum was as weak as $-5.4 \mathrm{~m} / \mathrm{s} / \mathrm{km}$. In this case, the $\mathrm{Na}_{\mathrm{s}}$ event exhibited a strong positive correlation with 


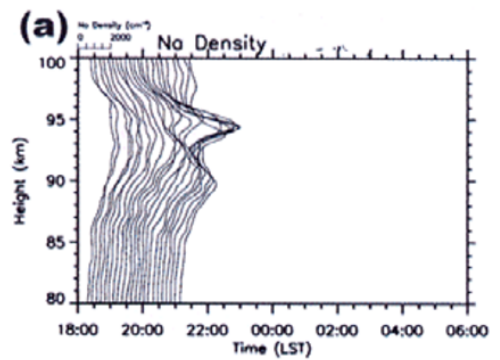

(d)



(g)

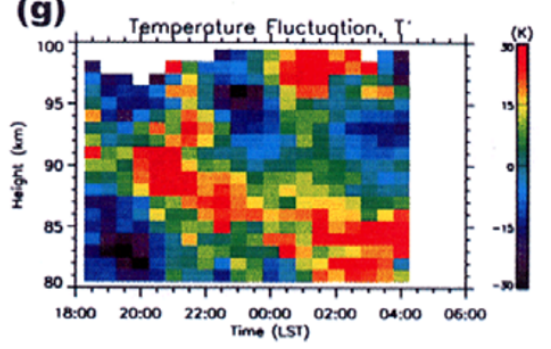

(b)

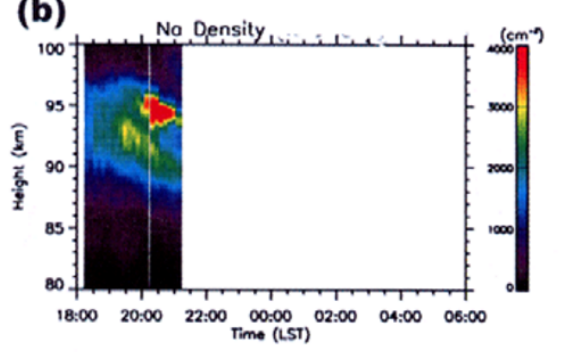

(e)

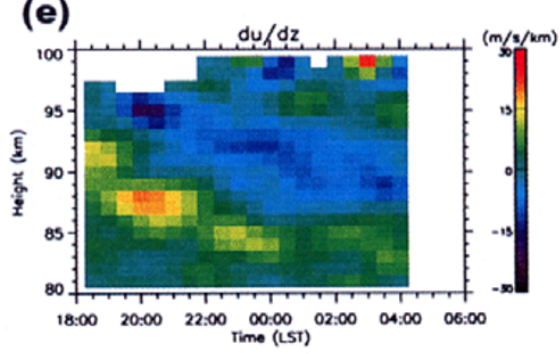

(h)

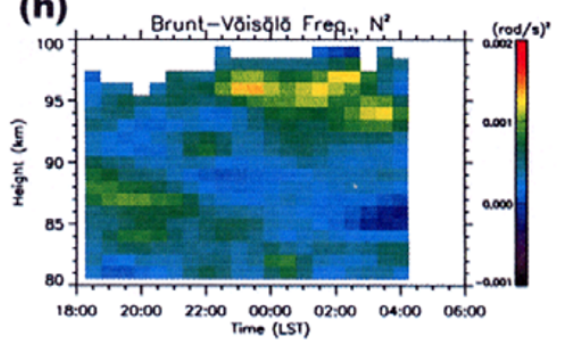

(c)

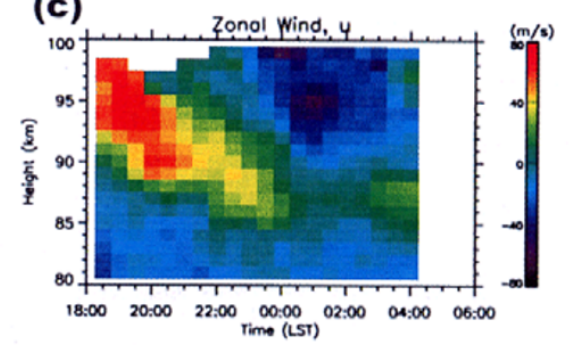

(f)
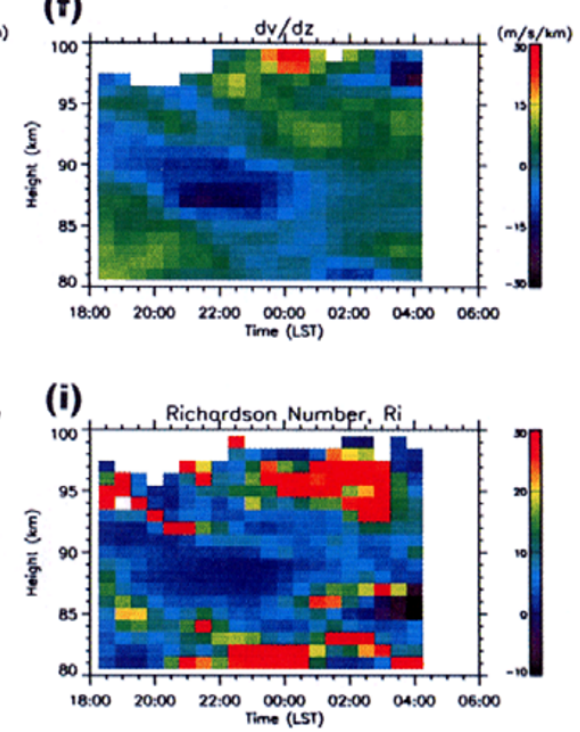

Fig. 6. (a), (b) Na density profiles and a contour plot obtained with the Hachioji Na lidar on September 20/21, 1995. Contour plots of the zonal (c) and meridional (d) wind velocities, zonal (e) and meridional (f) wind shears, temperature fluctuation (g), Brunt-Väisälä frequency squared (h), and Richardson number (i) observed simultaneously with the MU radar at Shigaraki.

the zonal wind shear. This strong shear could be caused by the superpositioning of multiple waves, as discussed above. As can be seen in Fig. 6, the temperature fluctuation, $T^{\prime}$, at the $\mathrm{Na}_{\mathrm{s}}$ peak was negative, and the Brunt-Väisälä frequency squared, $N^{2}$, was not very small. However, the Richardson number, $R i$, was as small as 1.1 , which corresponds to the strong zonal wind shear.

Another case study ivolving the comparison between the $\mathrm{Na}_{\mathrm{s}}$ and radar observations is shown in Fig. 7 for the data obtained at Hachioji on August 13/14, 1995. An $\mathrm{Na}_{\mathrm{s}}$ event reached the maximum density at 2:00 LST and $93 \mathrm{~km}$ altitude. The horizontal wind, $u$ and $v$, showed a strong wavelike structure with a period of about 15 hours, with an amplitude of over $50 \mathrm{~m} / \mathrm{s}$, which is considered to be an inertia gravity wave with upward energy propagation. The wind shears, $\mathrm{d} u / \mathrm{d} z$ and $\mathrm{d} v / \mathrm{d} z$, showed complicated variation, which again suggests superpositioning of multiple waves. However, a significant peak of $\mathrm{du} / \mathrm{dz}$ and $\mathrm{dv} / \mathrm{dz}$ was seen at the peak $\mathrm{Na}_{\mathrm{s}}$, although the direction of the shear was different from in the previous case.

On the other hand, around the time and height of the $\mathrm{Na}_{\mathrm{s}}$ event, temperature enhancement was observed. At the density maximum of the $\mathrm{Na}_{\mathrm{s}}$ event, $T^{\prime}$ was $29 \mathrm{~K}$, corresponding to the local maximum of $T^{\prime}$, where the absolute temperature, $T$, was $201 \mathrm{~K}$. The standard deviation of $T^{\prime}$ observed in this month was $15 \mathrm{~K}$, so the $T^{\prime}$ value of $29 \mathrm{~K}$ was consid- erably large in comparison with the standard deviation. In this case, the temperature enhancement and $\mathrm{Na}_{\mathrm{s}}$ occurrence were observed simultaneously, which is similar to the results obtained by Gardner et al. (1995).

In Fig. 7, the Richardson number, $R i$, at the maximum sodium density of $\mathrm{Na}_{\mathrm{s}}$, i.e., at 2:00 LST and $93.0 \mathrm{~km}$ altitude, was 1.2. The value of Brunt-Väisälä frequency squared, $N^{2}$, at that time and height was $6.1 \times 10^{-4}(\mathrm{rad} / \mathrm{sec})^{2}$, corresponding to 4.2 minutes in period. $N^{2}$ was slightly large compared to the average value of $4.9 \times 10^{-4}(\mathrm{rad} / \mathrm{sec})^{2}$ and the standard deviation of $3.1 \times 10^{-4}(\mathrm{rad} / \mathrm{sec})^{2}$. However, $R i$ was significantly smaller than the mean $R i$ in this month, which was 6.0. If we look for a local minimum of $R i$, it occurred at 2:00 LST and $94 \mathrm{~km}$ altitude, which is $1 \mathrm{~km}$ above the $\mathrm{Na}_{\mathrm{s}}$ layer, and the corresponding $R i$ was also 1.2 , and $R i$ did not become negative.

It is notable that the stability indices obtained in this study were for a fairly wide time and height scale with a resolution of $200 \mathrm{~km}$ in the horizontal extent and $2 \mathrm{~km}$ in thickness, considering the meteor echo distribution and smoothing procedure in the analysis. Thus, the indices here are mainly due to large scale atmospheric waves, such as tides and inertia gravity waves both of which have large amplitudes at this altitude range. Therefore, the superposed small scale gravity waves are likely to make the indices such as $N^{2}$ and $R i$ even smaller, and in the case in Fig. 7, it is probable that the 


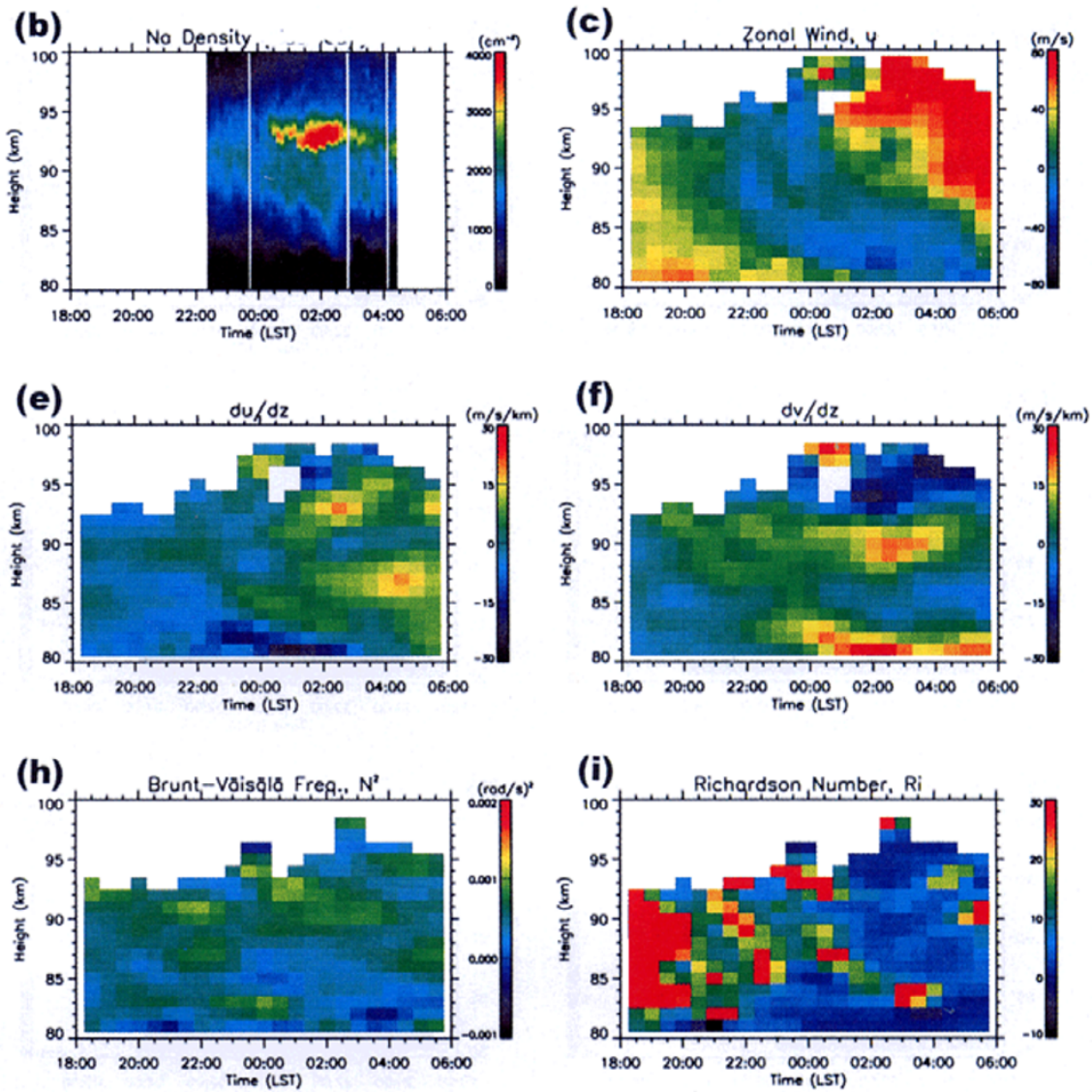

Fig. 7. The same as Fig. 6, except that the data are for August 13/14, 1995.

region of the $\mathrm{Na}_{\mathrm{s}}$ peak could be in the region of gravity wave breaking and subsequent heating, as supposed by Zhou et al. (1993).

\subsection{Simultaneous observation: statistical approach}

We perform the same analysis for all the $15 \mathrm{Na}_{\mathrm{s}}$ events observed, in order to discuss the dynamical background of $\mathrm{Na}_{\mathrm{s}}$ more statistically, although the number of samples is not so large. The results are summarized in Table 4 . The vertical shears of zonal and meridional winds, temperature fluctuations, Brunt-Väisälä frequencies, and Richardson numbers are estimated from the MU radar data at the time and altitude of the $\mathrm{Na}_{\mathrm{s}}$ density maximum.

The distribution of zonal wind shears at the $\mathrm{Na}_{\mathrm{s}}$ maximum density is plotted in the top panel of Fig. 8(a). The normalized shear, i.e., the wind shear normalized as to the standard deviation (r.m.s. amplitude) of the shear in each month, is plotted in the bottom panel of the same figure.

In Fig. 8(a), for seven of the $14 \mathrm{Na}_{\mathrm{s}}$ events, i.e., half the zonal shears, $\mathrm{d} u / \mathrm{d} z$, were shown to be westward, and the rest to be eastward. Similarly, northward and southward shears were evenly observed in Fig. 8(b). Thus, no clear preferential shear direction was found. For both zonal and meridional wind shears four of the 14 events showed more than twice the monthly standard deviation, and the number of cases with shears smaller than the standard deviation was small, as shown in the bottom panels of Fig. 8(a) and (b).

Considering the fact that there were many cases of strong shear of the horizontal wind, we now investigate the mag- nitud of the total shear of the horizontal wind, as shown in Fig. 8(c). The total wind shear normalized as to the mean amplitude in each month is also plotted in the bottom panel. It is notable that the statistical study on the MU radar wind data mentioned earlier in this paper showed that the occurrence rate of total shear exceeding the monthly mean is about $43 \%$, and only $6.2 \%$ of the data exceed twice the mean. On the other hand, for the amplitudes of the total shears of the horizontal wind at the $\mathrm{Na}_{\mathrm{s}}$ density maxima, eleven of the 14 events, i.e., $78 \%$, exhibit wind shears exceeding the monthly mean, and five, i.e., $35 \%$ of all events, exhibit shears of more than twice the monthly mean. Shears were less than the monthly mean for only three events, which is about $21 \%$ of all events. Therefore, the total wind shears around the time and altitude of $\mathrm{Na}_{\mathrm{s}}$ layers were significantly large for our observations, which is similar to the finding of Qian et al. (1998).

In order to confirm the significance of the wind shear around the $\mathrm{Na}_{\mathrm{s}}$, the distribution of normalized shears observed at $3 \mathrm{~km}$ below the $\mathrm{Na}_{\mathrm{s}}$ peak altitude is compared in Fig. 9. The wind shears at $3 \mathrm{~km}$ below were generally smaller. Although there were not many cases when the wind shear could be determined by means of radar observation at $3 \mathrm{~km}$ higher than $\mathrm{Na}_{\mathrm{s}}$, all three cases showed smaller wind shears than those at $\mathrm{Na}_{\mathrm{s}}$ peaks. Therefore, we can conclude that the total shear at the $\mathrm{Na}_{\mathrm{s}}$ peaks was considerably large, compared with both the statistical average and other heights.

It is noteworthy that among the seven $\mathrm{Na}_{\mathrm{s}}$ events with total 


\section{(a) Zonal shear at Nas peak}
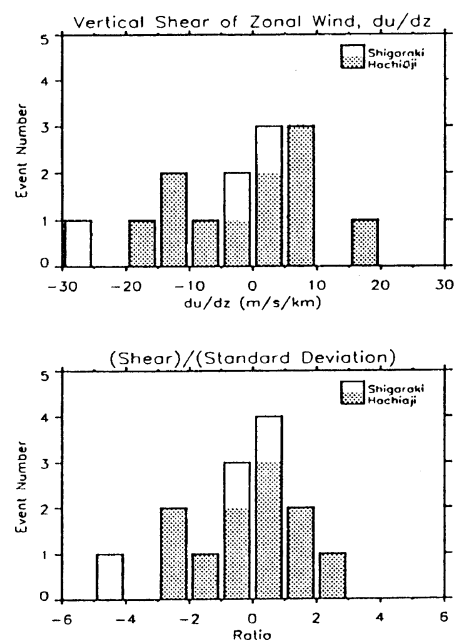

(b) Meridional Shear at Nas peak
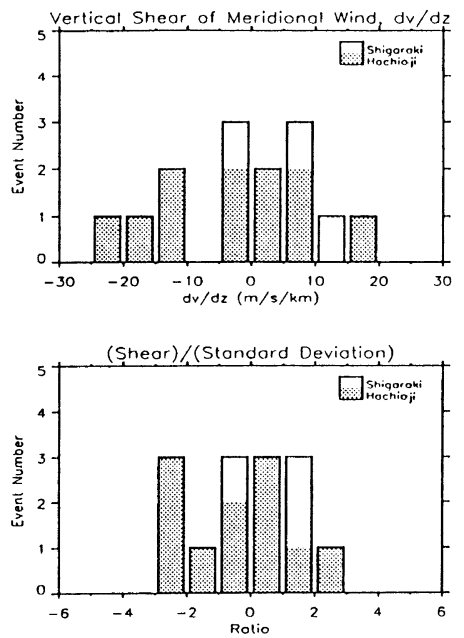

(c) Total shear at Nas peak
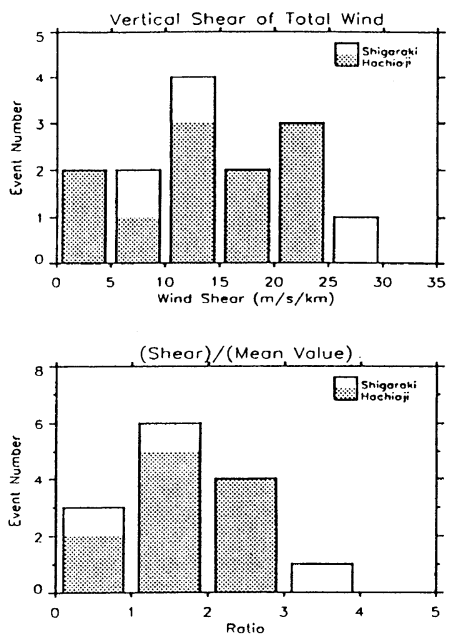

Fig. 8. Distributions of (a) zonal, (b) meridional and (c) total wind shears at the $\mathrm{Na}_{\mathrm{s}}$ density maximum. The top panels show the amplitudes of shear, while the bottom panels present the ratios, i.e., the wind shear normalized as to the standard deviation of the shear (a,b) or the average of the shear (c) in each month.

(a) Total shear at Nas peak

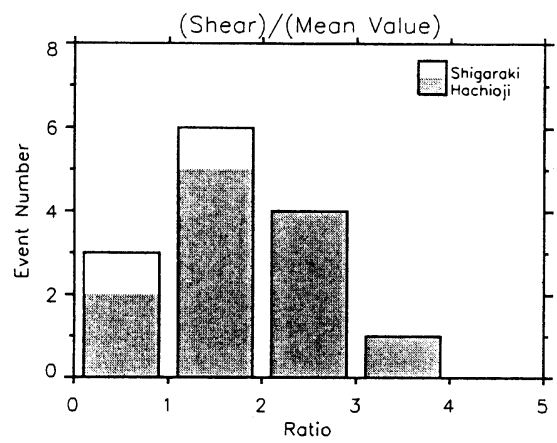

(b) at Nas peak $-3 \mathrm{~km}$

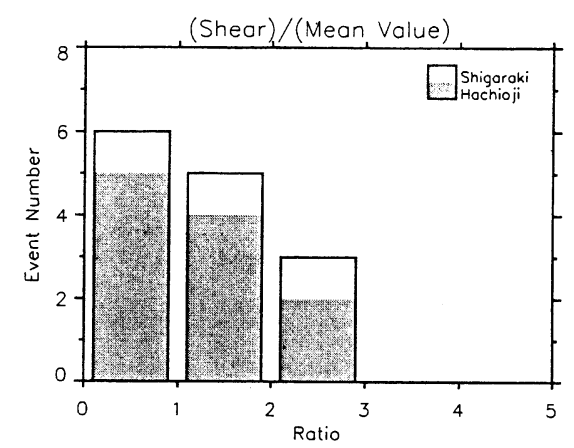

Fig. 9. Distributions of total wind shears at (a) the $\mathrm{Na}_{\mathrm{s}}$ density maximum, and (b) $3 \mathrm{~km}$ below the $\mathrm{Na}_{\mathrm{s}}$ density maximum. Total wind shears are normalized as to the monthly average.

wind shears exceeding 1.6 times the mean value, only one event was accompanied by Es. Therefore, the $\mathrm{Na}_{\mathrm{s}}$ events without an Es occurrence were more significantly correlated with strong total wind shears (see Fig. 10).

Next, we investigate the temperature at the times and heights of $\mathrm{Na}_{\mathrm{s}}$ events. The results shown in Table 4 are plotted as histograms in Fig. 11, where (a) temperature fluctuation, $T^{\prime}$, (b) normalized $T^{\prime}$ as to the standard deviation in each month, and (c) absolute temperature, $T$, at the $\mathrm{Na}_{\mathrm{s}}$ density maximum are displayed. In these figures, eight and five out of 13 events showed negative and positive temperature fluctuation, $T^{\prime}$, and therefore it is recognized that temperatures are rather lower at the times and heights of $\mathrm{Na}_{\mathrm{s}}$ occurrences than the average values. From these results, a correlation of $\mathrm{Na}_{\mathrm{s}}$ events with a temperature decrease, instead of enhancement which was proposed in the theory of
Zhou and Mathews (1995), is more probable, but it is difficult to conclude this definitely with the small samples in the current study.

Similarly, the Brunt-Väisälä frequency squared, $N^{2}$, and Richardson number, $R i$, are also investigated and plotted as histograms in Fig. 12 together with the $N^{2}$ fluctuations, $N^{2^{\prime}}$, i.e., normalized as to the standard deviation in each month. $N^{2}$ at the $\mathrm{Na}_{\mathrm{s}}$ density maximum seems to be mainly distributed between $2-6 \times 10^{-4}\left(\mathrm{rad}^{2} / \mathrm{sec}^{2}\right)$ and is close to the average values because the ratio is mainly distributed within \pm 0.5 . In comparison with the distribution of the average $R i$ presented in Fig. 2(f), the Richardson numbers were generally small for most of the $\mathrm{Na}_{\mathrm{s}}$ events. This finding is associated with the fact that large wind shears are observed at around the $\mathrm{Na}_{\mathrm{s}}$ density maximum. To summarize, the Brunt-Väisälä frequency, $N$, did not show the tendency of an 
Total shear at Nas peak

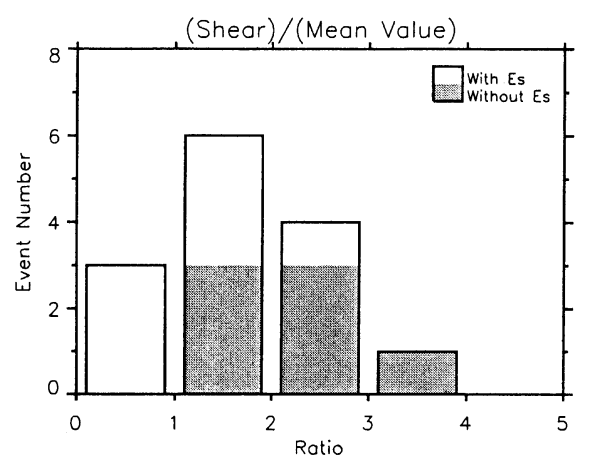

Fig. 10. Distributions of the total wind shear at the $\mathrm{Na}_{\mathrm{s}}$ density maximum. The shaded and open areas correspond to $\mathrm{Na}_{\mathrm{s}}$ events without and with an Es layer, respectively.

Temperature deviation at Nas peak
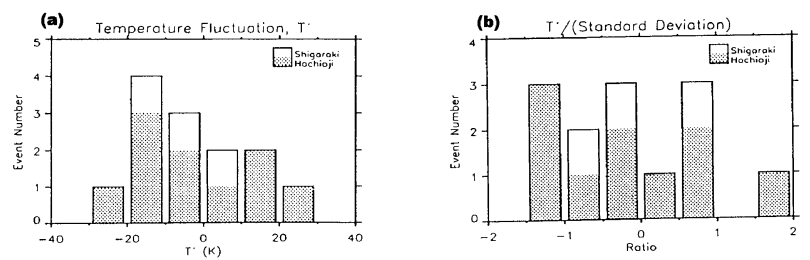

Temperature at Nas peak

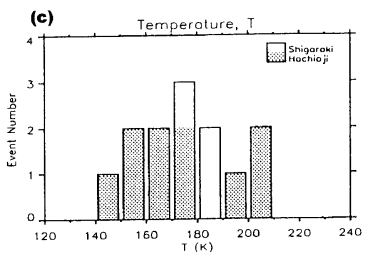

Fig. 11. Distributions of the temperature fluctuation, as presented in Fig. 8(a), (b), and temperature at the $\mathrm{Na}_{\mathrm{s}}$ density maximum (c).

Brunt-Väisälä frequency at Nas peak
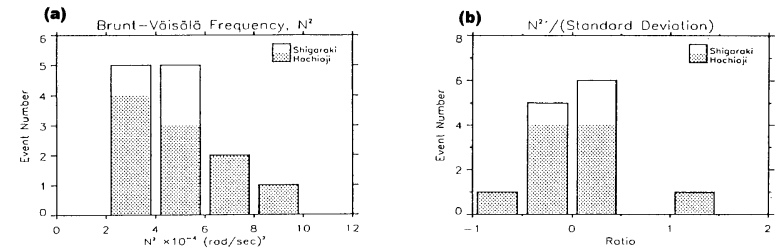

Richardson number at Nas peak

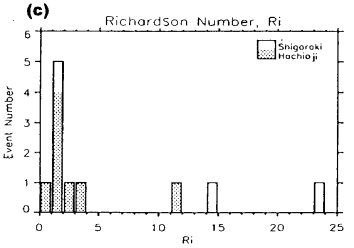

Fig. 12. Distributions of the Brunt-Väisälä frequency squared, $N^{2}$, as presented in Fig. 8(a), (b), and Richardson number at the $\mathrm{Na}_{\mathrm{s}}$ density maximum (c). unstable atmosphere, but the Richardson number, $R i$, was comparatively small.

\section{Discussion and Concluding Remarks}

Gardner et al. (1995) reported an $\mathrm{Na}_{\mathrm{s}}$ event accompanied with a strong wind shear observed by a $\mathrm{Na}$ wind/temperature lidar at Haleakala, Maui $\left(20.8^{\circ} \mathrm{N}, 156.2^{\circ} \mathrm{W}\right)$ during the ALOHA-93 campaign. On October 6, 1993, they observed a strong vertical shear of the zonal wind of $42 \mathrm{~m} / \mathrm{s} / \mathrm{km}$, which reached the shear instability limit under the assumption that the Brunt-Väisälä frequency corresponds to the period of 5 minutes at the altitude of $1 \mathrm{~km}$ below a prominent $\mathrm{Na}_{\mathrm{s}}$ layer. Qian et al. (1998) further investigated $43 \mathrm{Na}_{\mathrm{s}}$ events observed during the same campaign and concluded that strong shear of horizontal winds were observed during the majority of the $\mathrm{Na}_{\mathrm{s}}$ events and the maximum shears were located on average about $0.5 \mathrm{~km}$ below the $\mathrm{Na}_{\mathrm{s}}$ layer. In most cases, the meridional shears were significantly stronger than the zonal ones. The maximum total shears were generally directed to the north-northeast and to the south.

On the other hand, temperature variations are also thought to cause $\mathrm{Na}$ abundance variation through various chemical processes. Zhou et al. (1993) argued that a temperature fluctuation induced by gravity waves may cause $\mathrm{Na}_{\mathrm{s}}$ layer formation since the production rate of $\mathrm{Na}$ is known to be a sensitive function of temperature. The local enhancement of temperature caused by gravity wave breaking is thought to accelerate the chemical reaction generating atomic sodium from $\mathrm{Na}$ compounds. Gardner et al. (1995) observed two $\mathrm{Na}_{\mathrm{s}}$ events associated with temperature enhancement, which was more than $40 \mathrm{~K}$, on their sodium lidar observations, but on further analysis using the same dataset, Qian et al. (1998) found that the temperature enhancement was not always associated with $\mathrm{Na}_{\mathrm{s}}$ layers.

In this study, the correlations between the sporadic sodium layer at mid-latitude and dynamical parameters have been investigated by means of the MU radar and the two sodium lidars at Shigaraki and Hachioji. Because of the observational height range of the MU radar, comparisons were limited to the altitudes below $100 \mathrm{~km}$. Wind shears, temperature variations, and atmospheric stabilities indices have been investigated at the times and heights of occurrence of $\mathrm{Na}_{\mathrm{s}}$ layers detected by the sodium lidars.

In the current study, we have shown the case of an $\mathrm{Na}_{\mathrm{s}}$ event with a strong westward wind shear, and another case with a significant temperature increase. In both cases $R i$ was fairly small, as discussed in the previous section. However, in a statistical sense, by surveying all fifteen $\mathrm{Na}_{\mathrm{s}}$ events observed here, we can conclude that a strong wind shear is more likely to accompany the $\mathrm{Na}_{\mathrm{s}}$ occurrence. Especially when sporadic E layers were not existent, such shear was quite large. However, no other clear correlation with other dynamical parameters was seen in the comparisons. The results shown here are very similar to the report by Qian et al. (1998) on the lidar measurements during the ALOHA93 campaign in Hawaii $\left(\sim 20^{\circ} \mathrm{N}\right)$, and therefore it could be possible that the $\mathrm{Na}_{\mathrm{s}}$ in Hawaii and Japan, both located at a comparatively low latitude, are caused by a similar generation mechanism, although the details of the mechanism are not clear at the moment. We should also note that propa- 
gating diurnal tides (positive modes) in the horizontal winds are significantly strong at the latitudes of Hawaii and Japan (20-35 deg), and therefore the contribution of tides to the wind shears could be large, as well as inertia gravity waves.

In this study we have obtained some characteristics of $\mathrm{Na}_{\mathrm{s}}$ and associated dynamical characteristics of mid-latitude $\mathrm{Na}_{\mathrm{s}}$ layers. Further comparisons of radar and lidar measurements, with better time-height resolutions and preferably at the same location (in order to avoid the uncertainty of the spatial differences of dynamical parameters observed with the radar) in the future are desirable to clarify the generation mechanism of $\mathrm{Na}_{\mathrm{s}}$.

Acknowledgments. The MU radar belongs to and is operated by Radio Atmospheric Science Center, Kyoto University. The ionosonde data obtained at Kokubunji used in this study were provided by WDC-C2 for Ionosphere, Communications Research Laboratory, Japan.

\section{References}

Batista, P. P., B. R. Clemesha, and D. M. Simonich, Characteristics of the sporadic sodium layers observed at $23^{\circ}$ S, J. Geophys. Res., 94, 15349 15358, 1989.

Beatty, T. J., R. L. Collins, C. S. Gardner, C. A. Hostetler, C. F. Sechrist, Jr., and C. A. Tepley, Simultaneous radar and lidar observations of sporadic E and Na layers at Arecibo, Geophys. Res. Lett., 16, 1019-1022, 1989.

Clemesha, B. R., V. W. J. H. Kirchhoff, D. M. Simonich, and H. Takahashi, Evidence of an extra-terrestrial source for the mesospheric sodium layer, Geophys. Res. Lett., 5(10), 873-876, 1978.

Clemesha, B. R., V. W. J. H. Kirchhoff, D. M. Simonich, H. Takahashi, and P. P. Batista, Spaced lidar and nightglow observations of an atmospheric sodium enhancement, J. Geophys. Res., 85, 3480-3484, 1980.

Clemesha, B. R., P. P. Batista, and D. M. Simonich, Concerning the origin of enhanced sodium layers, Geophys. Res. Lett., 15, 1267-1270, 1988.

Clemesha, B. R., P. P. Batista, and D. M. Simonich, Formation of sporadic sodium layers, J. Geophys. Res., 101, 19701-19706, 1996.

Cox, R. M. and J. M. C. Plane, An ion-modecule mechanism for the formation of neutral sporadic Na layers, J. Geophys. Res., 103, 6349-6359, 1998.

Fukao, S., T. Sato, T. Tsuda, S. Kato, K. Wakasugi, and T. Makihira, The MU Radar with an active phased array system: 1. Antenna and power amplifiers, Radio Sci., 20, 1155-1168, 1985a.

Fukao, S., T. Tsuda, T. Sato, S. Kato, K. Wakasugi, and T. Makihira, The MU Radar with an active phased array system: 2. In-house equipment, Radio Sci., 20, 1169-1176, 1985b.

Gardner, C. S., D. G. Voelz, C. F. Sechrist, Jr., and A. C. Segal, Lidar studies of the nighttime sodium layer over Urbana, Illinois, 1, Seasonal and nocturnal variations, J. Geophys. Res., 91, 13659-13673, 1986.

Gardner, C. S., D. C. Senft, and K. H. Kwon, Lidar observations of a substantial sodium depletion in the summertime Arctic mesosphere, Nature, 332, 142-144, 1988.

Gardner, C. S., X. Tao, and G. C. Papen, Observations of strong wind shears and temperature enhancement during several sporadic $\mathrm{Na}$ layer events above Haleakala, Geophys. Res. Lett., 22(20), 2809-2812, 1995.

Granier, C. and G. Megie, Daytime lidar measurements of the mesospheric sodium layer, Planet. Space Sci., 30, 169-177, 1982.
Hansen, G. and U. von Zahn, Sudden sodium layers in polar latitudes, $J$. Atmos. Terr. Phys., 52, 585-608, 1990.

Kane, T. J., C. S. Gardner, Q. Zhou, J. D. Mathew, and C. A. Tepley, Lidar, radar and airglow observations of a prominent sporadic $\mathrm{Na}$ /sporadic $E$ layer event at Arecibo during AIDA-89, J. Atmos. Terr. Phys., 55(3), 499-511, 1993.

Kirkwood, S. and U. von Zahn, On the role of auroral electric fields in the formation of low altitude sporadic-E and sudden sodium layers, J. Atmos. Terr. Phys., 53, 389-407, 1991.

Kobayashi, K., T. Kitahara, T. D. Kawahara, Y. Saito, A. Nomura, T. Nakamura, T. Tsuda, M. Abo, C. Nagasawa, and M. Tsutsumi, Simultaneous measurements of dynamical structure in the mesopause region with lidars and MU radar, Earth Planets Space, 51, this issue, 731-739, 1999.

Kwon, K. H., D. C. Senft, and C. S. Gardner, Lidar observations of sporadic sodium layers at Mauna Kea Observatory, Hawaii, J. Geophys. Res., 93, 14,199-14,208, 1988.

Nagasawa, C. and M. Abo, Lidar observations of a lot of sporadic sodium layers in mid-latitude, Geophys. Res. Lett., 22(3), 263-266, 1995.

Nakamura, T., T. Tsuda, M. Tsutsumi, K. Kita, T. Uehara, S. Kato, and S. Fukao, Meteor wind observations with the MU radar, Radio Sci., 26, 857-869, 1991.

Nakamura, T., T. Tsuda, S. Fukao, H. Takahashi, P. P. Batista, R. A. Buriti, M. Tsutsumi, M. Ishii, K. Igarashi, H. Fukunishi, Y. Yamada, A. Nomura T. D. Kawahara, K. Kobayashi, C. Nagasawa, M. Abo, and M. J. Taylor, Studies of the MLT regions using the MU radar and simultaneous observations with $\mathrm{OH}$ spectrometer and other optical instruments, $A d v$. Space Res., 19, 643-652, 1997.

Namboothiri, S. P., T. Tsuda, M. Tsutsumi, T. Nakamura, C. Nagasawa, and M. Abo, Simultaneous observations of mesospheric gravity waves with the MU radar and a sodium lidar, J. Geophys. Res., 101, 4057-4063, 1996.

Nomura, A., T. Kano, Y. Iwasaka, H. Fukunishi, T. Hirasawa, and S. Kawaguchi, Lidar observations of the mesospheric sodium layer at Syowa station, Antarctica, Geophys. Res. Lett., 14, 700-703, 1987.

Qian, J., Y. Gu, and C. S. Gardner, Characteristics of the sporadic Na layers observed during the ALOHA/ANLC-93 campaigns, J. Geophys. Res., 103(D6), 6333-6347, 1998.

Tsutsumi, M., T. Tsuda, T. Nakamura, and S. Fukao, Wind velocity and temperature fluctuations due to a 2-day wave observed with radio meteor echoes, J. Geophys. Res., 101(D5), 9425-9432, 1996.

von Zahn, U., P. von der Gathen, and G. Hansen, Forced release of sodium from upper atmospheric dust particles, Geophys. Res. Lett., 14, 76-79, 1987.

von Zahn, U. and T. L. Hansen, Sudden neutral sodium layers: a strong link to sporadic E layers, J. Atmos. Terr. Phys., 50, 93-104, 1988.

von Zahn, U. and E. Murad, $\mathrm{NaHCO} 3$, a source of $\mathrm{Na}$ atoms for sudden sodium layers, Geophys. Res. Lett., 17, 147-150, 1990.

Zhou, Q. and J. D. Mathews, Generation of sporadic sodium layers via turbulent heating of the atmosphere?, J. Atmos. Terr. Phys., 57(11), 13091319, 1995.

Zhou, Q., J. D. Mathews, and C. A. Tepley, A proposed temperature dependent mechanism for the formation of sporadic sodium layers, J. Atmos. Terr. Phys., 55(3), 513-521, 1993.

H. Miyagawa (e-mail: hirohisa@sd5.so-net.ne.jp), T. Nakamura, T. Tsuda, M. Abo, C. Nagasawa, T. D. Kawahara, K. Kobayashi, T. Kitahara, and A. Nomura 